\title{
Update on the Society for Disaster Medicine and Public Health
}

\author{
James J. James, MD, DrPh, MHA, Editor-in-Chief
}

$\mathrm{T}$ his is a brief informational note for our readers. We are now ready to process memberships and subscriptions through our website (https:// sdmph.org/). A fully vested, voting membership level will be available with dues at $\$ 200$ per annum based on a calendar year. This membership level will include an electronic subscription to our journal (DMPHP), special educational benefits, eligibility for our certificate program (details to follow), and voting privileges in accordance with our bylaws at our annual business meeting, which will be held later this year. A second level of affiliate membership will be offered to those who wish to support our goals but not as an active society member. This level will be at $\$ 100$ per annum and members will receive an electronic subscription to our journal. Finally, a student membership level will be offered at $\$ 30$ per annum that will include the electronic journal subscription. Individuals at all levels who wish to receive a print subscription to DMPHP can do so for an additional fee of $\$ 100$. Individuals just wanting an electronic journal subscription can do so for $\$ 200$. And, of course, any individuals desiring to support us through a tax-deductible contribution are encouraged to do so.

Second, I would like to alert all to the announcement of our Annual Meeting, which will be held in the area of Norfolk, VA, September 26-29 in partnership with the USNS Comfort medical personnel and will include presentations and tours of the hospital ship. Please go to our website (https://sdmph.org/) for additional information.

\section{Cover Image:}

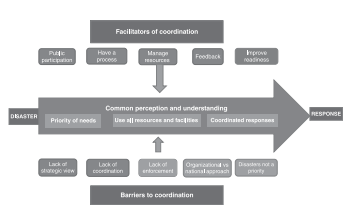

Adapted from Figure 1, Bahadori et al, doi:10.1017/dmp.2016.131, page 321 